\title{
Network-Constrained Multiperiod Auction for Pool-Based Electricity Markets of Hydrothermal Systems
}

\author{
Augusto Cesar Pereira, Alberto Quialheiro de Oliveira, Edméa Cássia Baptista, Antonio Roberto Balbo, \\ Edilaine Martins Soler, and Leonardo Nepomuceno ${ }^{(\mathbb{1})}$, Member, IEEE
}

\begin{abstract}
Network-constrained market clearing procedures in pool-based electricity markets of hydropower systems have traditionally neglected the constraints associated with physical and operating aspects of hydroelectric generation (hydraulic constraints). Such constraints are generally taken into account by means of $e x$ post procedures, which may lead to suboptimal results regarding social welfare function. This paper proposes a network-constrained auction model for hydrothermal systems that represents the hydraulic constraints in detail. The objectives of the paper are twofold: the analysis of the impact of hydraulic constraints on market clearing prices and on generation/consumption scheduling and the analysis of the influence of strategic offering of hydro plants in the operation of a hydraulic cascade. As some of the hydraulic constraints are nonlinear and intertemporal, linearization techniques are applied, resulting in a mixed-integer linear programming problem.
\end{abstract}

Index Terms-Hydrothermal systems, linearization, market clearing procedure, mixed-integer linear programing.

\section{NOMENCLATURE}

\section{Constants}

$\alpha_{0 a}, \ldots, \alpha_{4 a}$

Parameters of the nonlinear fore-bay elevation function of plant $a[\mathrm{~m}]$.

$\alpha_{b, r, \rho}$

Slope of the angle block $\rho$ of the linearized voltage angle difference in transmission line $(b, r)[\mathrm{rad}]$.

$\beta_{0 a}, \ldots, \beta_{4 a}$ Parameters of the nonlinear tail-race elevation function of plant $a[\mathrm{~m}]$.

$\lambda_{m, i}(k)$ Price of the $m$ th energy block offered by generating station $i$ in period $k$ [\$/MWh].

$\lambda_{n, j}(k) \quad$ Price of the $n$th energy block bid by consumer $j$ in period $k$ [\$/MWh].

Manuscript received June 24, 2016; revised November 23, 2016 and January 26, 2017; accepted March 11, 2017. Date of publication March 21, 2017; date of current version October 18, 2017. Paper no. TPWRS-00915-2016.

A. C. Pereira and A. Q. de Oliveira are with the Post-Graduate Program in Electrical Engineering, Engineering Faculty, Universidade Estadual Paulista, Bauru, Brazil (e-mail: augusto.pereira@feb.unesp.br; beto.stanley@bol.com.br).

E. C. Baptista, A. R. Balbo, and E. M. Soler are with the Department of Mathematics, Science Faculty, Universidade Estadual Paulista, Bauru, Brazil (email: baptista@fc.unesp.br; arbalbo@fc.unesp.br; edilaine@fc.unesp.br).

L. Nepomuceno is with the Department of Electrical Engineering, Engineering Faculty, Universidade Estadual Paulista, Bauru, Brazil (e-mail: leo@feb.unesp.br).

Digital Object Identifier 10.1109/TPWRS.2017.2685245

$\Delta \delta_{\rho}$
$\Psi_{a}(k)$
$D_{a}^{\omega}$
$D_{1}$
$D_{2}$
$F_{b, r}$
$F_{c}$
$G_{b, r}$
$G_{c}$

$H_{a}^{x, y}$

$H_{a}^{e f}$

$H D_{a_{0}}, H D_{a_{1}}$

$\overline{H U}_{a}, \underline{H U}_{a}$

$L_{a}$

$N B$

$P^{\text {base }}$

$P^{e f}$

$\bar{P}_{i}(k), \underline{P}_{i}(k)$

$\bar{P}_{m, i}^{G}(k)$

$\bar{P}_{n, j}^{D}(k)$

$Q_{a}^{e f}$

$Q_{a}^{x, y}, P_{a}^{x, y}$

$R_{a}$

$R U_{c}, R D_{c}$
Upper bound on the piecewise angle block $\rho$ [rad].

Inflow to reservoir $a$ in period $k\left[\mathrm{~m}^{3} / \mathrm{s}\right]$.

Water delay time between plant $\omega$ and the downstream plant $a[\mathrm{~h}]$.

Constant equal to 0.0036 .

Constant equal to $9.81 \times 10^{-3}$.

Active power capacity of transmission line $(b, r)$ [MW].

Number of periods unit $c$ must be offline at the beginning of the market horizon due to its minimum down time constraint [h].

Conductance of transmission line $(b, r)$ [pu]. Number of periods unit $c$ must be online at the beginning of the market horizon due to its minimum up time constraint [h].

Net head of plant $a$ at data point $(x, y)$ in the interpolation of the performance curve [m].

Effective net head of plant $a[\mathrm{~m}]$.

Parameters of the linearized tail-race elevation function of plant $a[\mathrm{~m}]$.

Maximum/minimum fore-bay elevation of plant $a[\mathrm{~m}]$.

Loss constant of plant $a(\%)$.

Number of angle blocks.

Power base of the system [MW].

Effective power of plant $a$ [MW].

Maximum/minimum power output of generating station $i$ in period $k$, given by: $\bar{P}_{i}(k)=\sum_{m \in M_{i}(k)} \bar{P}_{m, i}^{G}(k)$ and $\underline{P}_{i}(k)=$ $\bar{P}_{1, i}^{G}(k)$, respectively [MW].

Upper limit of the $m$ th energy block offered by generating station $i$ in period $k$ [MW].

Upper limit of the $n$th energy block bid by consumer $j$ in period $k$ [MW].

Effective water discharge of plant $a[\mathrm{~m}]$.

Water discharge/power output from plant $a$ at data point $(x, y)$, in the interpolation of the performance curve $\left[\mathrm{m}^{3} / \mathrm{s}\right] /[\mathrm{MW}]$.

Release ramp rate for plant $a\left[\mathrm{~m}^{3} / \mathrm{s} / \mathrm{h}\right]$.

Ramp-up/Ramp-down limit of unit $c[\mathrm{MW} / \mathrm{h}]$. 


\begin{tabular}{|c|c|c|}
\hline $\bar{S}_{a}, \underline{S}_{a}$ & $\begin{array}{l}\text { Maximum/minimum spillage from plant } a \\
{\left[\mathrm{~m}^{3} / \mathrm{s}\right]}\end{array}$ & \\
\hline$S B_{i}$ & Start-up offer of generating station $i[\$$. & \\
\hline$S U_{c}, S D_{c}$ & $\begin{array}{l}\text { Start-up/shut-down ramp limit of unit } c \\
{[\mathrm{MW} / \mathrm{h}] \text {. }}\end{array}$ & \\
\hline$T$ & Number of auction periods. & \\
\hline $\bar{U}_{a}, \underline{U}_{a}$ & $\begin{array}{l}\text { Maximum/minimum water release from plant } \\
a\left[\mathrm{~m}^{3} / \mathrm{s}\right] \text {. }\end{array}$ & \\
\hline$U T_{c}, D T_{c}$ & Minimum up/down time of unit $c[\mathrm{~h}]$. & \\
\hline & $\begin{array}{l}\text { Maximum/minimum water volume in reser- } \\
\text { voir } a\left[\mathrm{hm}^{3} \text {. }\right.\end{array}$ & \\
\hline$V_{a}(0), V_{a}(T)$ & $\begin{array}{l}\text { Water volume for reservoir } a \text { at the end of } \\
\text { periods } k=0 \text { and } k=T \text {, respectively [ } \mathrm{hm}^{3} \text {. }\end{array}$ & \\
\hline$X_{b, r}$ & Reactance of transmission line $(b, r)[\mathrm{pu}]$. & \\
\hline $\bar{Z}_{a}$ & Maximum number or start-ups of plant $a$. & \\
\hline \multicolumn{2}{|c|}{ Variables and Functions } & \\
\hline$\delta_{b}(k)$ & Voltage angle in bus $b$ [rad]. & \\
\hline$\delta_{b} \quad(k)$ & $\begin{array}{l}\text { Angle block } \rho \text { relative to the transmission line } \\
(b, r) \text { in period } k \text { [rad]. }\end{array}$ & \\
\hline$\delta_{b, r}^{a b s}(k)$ & $\begin{array}{l}\text { Absolute value of the voltage angle difference } \\
\text { in transmission line }(b, r) \text { in period } k \text { [rad]. }\end{array}$ & \\
\hline$\delta_{b, r}^{+}(k), \delta_{b, r}^{-}(k)$ & $\begin{array}{l}\text { Auxiliary variables used in the linear formula- } \\
\text { tion of the absolute value of the voltage angle } \\
\text { difference in transmission line }(b, r) \text { in period } \\
k \text { [rad]. }\end{array}$ & \\
\hline$a_{a}^{t g}(k)$ & $\begin{array}{l}\text { Turbine-generator efficiency of the units of } \\
\text { plant } a \text { in period } k \text {. }\end{array}$ & \\
\hline
\end{tabular}

$f_{b, r}(k) \quad$ Active power flow in transmission line $(b, r)$ in period $k$ [MW].

$h_{a}(k) \quad$ Net head of reservoir $a$ in period $k[\mathrm{~m}]$.

$h u_{a}(k), h d_{a}(k)$ Fore-bay/tail-race elevation of reservoir $a$ in period $k[\mathrm{~m}]$.

$p_{i}(k) \quad$ Power output of generating station $i$ in period $k$ [MW].

$\bar{p}_{i}(k) \quad$ Maximum available power output from generating station $i$ in period $k$ [MW].

$p_{m, i}^{G}(k) \quad$ Power produced from the $m$ th energy block offered by station $i$ in period $k$ [MW].

$p_{n, j}^{D}(k) \quad$ Power consumed from the $n$th energy block bid by consumer $j$ in period $k$ [MW].

$p_{b, r}^{\text {loss }}(k) \quad$ Active power losses in transmission line $(b, r)$ in period $k$ [pu].

$q_{a}(k), s_{a}(k) \quad$ Water discharge/spillage from plant $a$ in pe$\operatorname{riod} k\left[\mathrm{~m}^{3} / \mathrm{s}\right]$.

$\bar{q}_{a}(k) \quad$ Maximum available water discharge from plant $a$ in period $k\left[\mathrm{~m}^{3} / \mathrm{s}\right]$.

$u_{a}(k) \quad$ Total water release from plant $a$ in period $k$ $\left[\mathrm{m}^{3} / \mathrm{s}\right]$.

$v_{a}(k), \bar{v}_{a}(k) \quad$ Volume/average volume of reservoir $a$ in pe$\operatorname{riod} k\left[\mathrm{hm}^{3}\right.$.

$w_{a}^{x, y}(k) \quad$ Weight of data point $(x, y)$, of plant $a$ in period $k$.

$z_{i}(k) \quad$ Binary variable which is equal to 1 if the generating station $i$ is on-line in period $k$.

$z d_{i}(k) \quad$ Binary variable which is equal to 1 if the generating station $i$ is shut-down in period $k$.
Binary variable for plant $a$ in period $k$ which is equal to 1 if the interpolation cell is in the upper quadrangle.

Binary variable which is equal to 1 if the generating station $i$ is started-up in period $k$.

Transmission lines.

Upstream plants of plant $a$.

Hydroeletric plants/reservoirs.

Buses.

Thermal generating units.

Generating stations $(A \cup C)$.

Consumers.

Periods of the auction model.

Energy block offered by generating station $i$ in period $k$.

Mapping of the consumers into the grid.

Mapping of the generating stations into the grid.

Energy block bid by consumer $j$ in period $k$. sets of data points $(x, y)$ used in the interpolation of the performance curve.

\section{INTRODUCTION}

receives energy offers and bids from producers and consumers, respectively, and calculates the market equilibrium by means of a Network-Constrained Market Clearing Procedure (NCMCP). The NCMCP calculates accepted offers and bids as well as market clearing prices for each period of the following day. It is desirable that the NCMCP calculates a feasible generation scheduling, therefore, the representation of physical and operational limits of the systems is generally incorporated into the model.

Neglecting physical and operational aspects of the thermal generation system (e.g. ramp-up/down limits, minimum up/down times, etc.) in NCMCP models may compromise the solution calculated [1]. When such aspects are neglected in the NCMCP, ex post adjustments in generation scheduling and market clearing prices are generally necessary, which may result in sub-optimality of the social welfare function [2]. Analogously, in this paper we argue that neglecting the representation of constraints associated with the hydro generation system (e.g. limits in water volumes in reservoirs, water release and spillage, hydraulic balance equations, hydro generation function, ramp rates in water release, etc.) may have a significant impact in market clearing prices as well as in generation/consumption commitment.

Neglecting hydro constraints in NCMCP models for hydropower systems may lead to problems such as: i) the NCMCP model may produce infeasible generation scheduling regarding hydro constraints, which may necessitate ex post corrections and, as a consequence, may lead to sub-optimality of the social welfare function; ii) the NCMCP model may provide unrealistic 
market clearing prices; iii) the NCMCP model may provide a generation scheduling that is not coordinated with higher-level planning model, in terms of future water availability, which may implicate in future water scarcity or waste.

To account for such modeling issues, we propose a multiperiod NCMCP model for hydrothermal systems which represents detailed hydraulic, thermal and network constraints. To cope with the nonlinear and/or non-convex hydraulic constraints [3], [4], we propose specific linearization strategies, so as to formulate the model by means of a Mixed-Integer Linear Problem (MILP). The NCMCP here proposed presents the following contributions: i) hydraulic constraints such as reservoir water balance, limits in water release, spillage and reservoir volume, as well as the limits in ramp rate releases of reservoirs are formulated; ii) fore-bay and tail-race elevation functions of the reservoirs are represented by appropriate linearization; iii) a three-dimensional interpolation technique is adapted to handle the nonlinear nature of the hydro production function.

We assume that offers from thermal producers are provided by generating units [1], [5], [6], while offers from hydro producers are provided by the plant, and not by its units, due to the following reasons: i) inter-temporal hydraulic constraints are related to the plant (reservoir) as a whole, and not to its units; ii) in a hydrothermal system, security and reliability are associated with water availability, i.e., they are related to the reservoir operation, and not to the operation of the units. So, despite neglecting individualized operation of units, modeling hydro generation per plant does not compromise operational security and inter-temporal constraints. Finally, the transmission system is represented in detail including network congestion and losses, as described in [5]. The solutions obtained with the proposed model has two main objectives: to evaluate the impact of hydraulic constraints on hourly market clearing prices and scheduling, and the evaluation of the impact of offer block prices of hydro plants in the hydraulic operation of a cascade. The impact of the transmission system on market clearing prices and scheduling is also analyzed.

The authors are not aware of any previous day-ahead auction models for pool-based electricity markets of hydrothermal systems that explicitly represents the hydraulic constraints. All auction models investigated for hydro-dominated systems focus on purely economic market clearing procedures which ignore technical and operational constraints of hydro units, as well as transmission system representation. In the model here proposed, hydraulic constraints are based on formulations described in short-term hydrothermal scheduling problems [3], [7], [8], and also in profit maximization problems, such as: strategic bidding [9], [10] and self-scheduling[4], [11], [12]. In this paper, we discuss the hydraulic constraints in the context of auction models for hydrothermal systems, in what concerns the linearization strategies adopted as well as the representation of nonlinear head effect.

This paper is organized as follows: Section II presents the nonlinear mathematical formulation of the proposed model, Section III presents the proposed linearization techniques, Sec- tion IV summarizes the proposed mixed-integer linear NCMCP model, Section $\mathrm{V}$ analyzes the solutions obtained for the case studies and Section VI provides the conclusions.

\section{NONLINEAR MATHEMATICAL FORMULATION}

This section presents the nonlinear mathematical formulation of the NCMCP model. For consistency of constants and units, we consider periods of one hour. Constraints that apply only to the thermal generation, which model the available power output of units in each period, ramp-up, ramp-down, start-up and shutdown ramp rate limits, and minimum up and down times, are presented in [1] and [13] and rewritten in Appendix A, for completeness. Network constraints, which involve nodal power balance, limits in active power flows and power losses, were extracted from [5], where the transmission losses and active power flows are properly linearized. These constraints are also rewritten in Appendix B.

\section{A. Objective Function}

The goal of the MO is to maximize the declared net social welfare, which is defined as the sum of consumer and producer surpluses [14]. Mathematically, this criterion is expressed as:

$$
\begin{aligned}
\text { Maximize } & \sum_{k \in K} \sum_{j \in J} \sum_{n \in N_{j}} \lambda_{n, j}(k) p_{n, j}^{D}(k) \\
& -\sum_{k \in K} \sum_{i \in I}\left[\sum_{m \in M_{i}} \lambda_{m, i}(k) p_{m, i}^{G}(k)+S B_{i} z u_{i}(k)\right] .
\end{aligned}
$$

In (1), the first term is related to the buying bid blocks, whereas the second term is related to the selling offer blocks, which can include start-up offer prices [1] for thermal units and/or hydro plants. Although there are some studies concerning the evaluation of start-up and shut-down costs for hydro units [15], [16], these aspects are not included in our model, since, as already explained, we do not represent individual hydro units, but the whole plant.

\section{B. Power limits}

Limits in power output of the generating stations (thermal units and hydro plants) are described in (2)-(4):

$$
\begin{aligned}
p_{i}(k) & =\sum_{m \in M_{i}(k)} p_{m, i}^{G}(k), \forall i \in I, \forall k \in K, \\
p_{i}(k) & \geq \underline{P}_{i}(k) z_{i}(k), \forall i \in I, \forall k \in K, \\
p_{m, i}^{G}(k) & \leq \bar{P}_{m, i}^{G}(k), \forall m \in M_{i}(k), \forall i \in I, \forall k \in K .
\end{aligned}
$$

The constraints (2) set the power output of a generating station as the sum of the accepted energy offer blocks. The constraints (3) establish minimum power output for a generating station, in case this station is on. The constraints (4) limit the accepted power output from each energy block to its upper limit. 


\section{Water Discharge, Spillage and Water Release}

The constraints related to the water release are given from (5) to (7):

$$
\begin{gathered}
u_{a}(k)=q_{a}(k)+s_{a}(k), \forall a \in A, \forall k \in K, \\
\underline{U}_{a} \leq u_{a}(k) \leq \bar{U}_{a}, \forall a \in A, \forall k \in K, \\
\underline{S}_{a} \leq s_{a}(k) \leq \bar{S}_{a}, \forall a \in A, \forall k \in K .
\end{gathered}
$$

The constraints (5) define the total water release from a hydro plant as the sum of water discharge and spillage. Constraints (6) and (7) establish lower and upper limits for water discharge and spillage. For some hydro plants, a minimum spillage may be necessary in order to preserve aquatic fauna of the spillway channel [17].

\section{Water Release Ramp Rates}

According to [17], water release ramp rates must be enforced, so as to avoid environmental problems and to ensure navigability. As in [18], the water release ramp rates are described by (8):

$$
\begin{gathered}
u_{a}(k)-R_{a} \leq u_{a}(k+1) \leq u_{a}(k)+R_{a}, \forall a \in A, \\
\forall k \in\{1, \ldots, T-1\} .
\end{gathered}
$$

\section{E. Reservoir Volume}

Constraints involving volumes are given in (9)-(12):

$$
\begin{aligned}
& \underline{V}_{a} \leq v_{a}(k) \leq \bar{V}_{a}, \forall a \in A, \forall k \in K, \\
& v_{a}(T) \geq V_{a}(T), \forall a \in A, \\
& \bar{v}_{a}(k)= \frac{v_{a}(k)+v_{a}(k-1)}{2}, \forall a \in A, \\
& \forall k \in\{2, \ldots, T\}, \\
& \bar{v}_{a}(1)=\frac{v_{a}(1)+V_{a}(0)}{2}, \forall a \in A .
\end{aligned}
$$

The constraints (9) set minimum and maximum limits for reservoir volumes. It is noteworthy that these are not the physical limits of the reservoir, but the limits previously established for the day. Constraints (10) set de reservoir minimum volume for the last period of the day. These constraints coordinate shortterm generation scheduling calculated by the auction model with medium-term decisions. Other forms of coordination are discussed in [19] and [20]. Constraints (11) and (12) define the medium volume of a reservoir as the average reservoir volume in two consecutive periods.

\section{F. Nodal Water Balance}

Water balance equations are shown in (13) and (14):

$$
\begin{aligned}
v_{a}(k)= & v_{a}(k-1)+D_{1}\left[\Psi_{a}(k)+\rho_{a}(k)\right. \\
& \left.-u_{a}(k)\right], \forall a \in A, \forall k \in\{2, \ldots, T\},
\end{aligned}
$$

where:

$$
\begin{aligned}
& \rho_{a}(k)= \begin{cases}\sum_{\omega \in \Omega_{a}} u_{\omega}\left[k-D_{a}^{\omega}\right], & \text { if } k-D_{a}^{\omega} \geq 1 \\
0, & \text { otherwise, }\end{cases} \\
& v_{a}(1)=V_{a}(0)+D_{1}\left[\Psi_{a}(1)-u_{a}(1)\right], \forall a \in A .
\end{aligned}
$$

The constraints (13) represent the water balance between two consecutive periods in the market horizon. Note that the water delay between two reservoirs in a cascade is represented in [21]. Constraints (14) represent the water balance for the first period in the market horizon, considering the reservoir initial volume.

\section{G. Reservoir Fore-bay and Tail-race Elevations}

Fore-bay and tail-race elevations are generally formulated as a fourth order polynomial function of the reservoir volume and water release, respectively, as in (15) and (16):

$$
\begin{aligned}
h u_{a}(k)= & \alpha_{0 a}+\alpha_{1 a} \bar{v}_{a}(k)+\alpha_{2 a} \bar{v}_{a}^{2}(k) \\
& +\alpha_{3 a} \bar{v}_{a}^{3}(k)+\alpha_{4 a} \bar{v}_{a}^{4}(k), \forall a \in A, \forall k \in K, \\
h d_{a}(k)= & \beta_{0 a}+\beta_{1 a} u_{a}(k)+\beta_{2 a} u_{a}^{2}(k) \\
& +\beta_{3 a} u_{a}^{3}(k)+\beta_{4 a} u_{a}^{4}(k), \forall a \in A, \forall k \in K .
\end{aligned}
$$

These head functions are linearized in our model, as described in Section III-A.

\section{H. Reservoir Net head}

The constraints (17) set the reservoir net head as the difference between the gross head and the penstock head loss. Penstock head losses are formulated as a fraction $L_{a}$ of the gross head:

$$
\begin{aligned}
h_{a}(k)= & \left(1-L_{a}\right)\left[h u_{a}(k)-h d_{a}(k)\right], \\
& \forall a \in A, \forall k \in K .
\end{aligned}
$$

\section{Hydroelectric Power Generation Function}

The hydroelectric power generation function for a generating unit is given by (18):

$$
p_{a}(k)=D_{2} \eta_{a}^{t g}(k) q_{a}(k) h_{a}(k), \forall a \in A, \forall k \in K,
$$

where turbine-generator efficiency and net head are a nonlinear and non-convex functions [22]. In this paper the power generation function is represented by unit performance curves as described in [3], [23], which relate power output and water discharge, parameterized at specific net head values. Note that if we fix the net head value in the power production function the relation between power output and water discharge is still nonlinear, due to nonlinearities in turbine-generator efficiency. The power production function is represented by a linear model in Section III-B.

\section{J. Maximum Power Output and Water Discharge}

Both, the maximum power output $\bar{p}_{a}(k)$ and the water discharge $\bar{q}_{a}(k)$ of a generating unit, are functions of the net head, as shown in Fig. 1. Note that in the first part of the curve, the maximum power output and water discharge are limited by the maximum power supported by the turbine, while in the right 

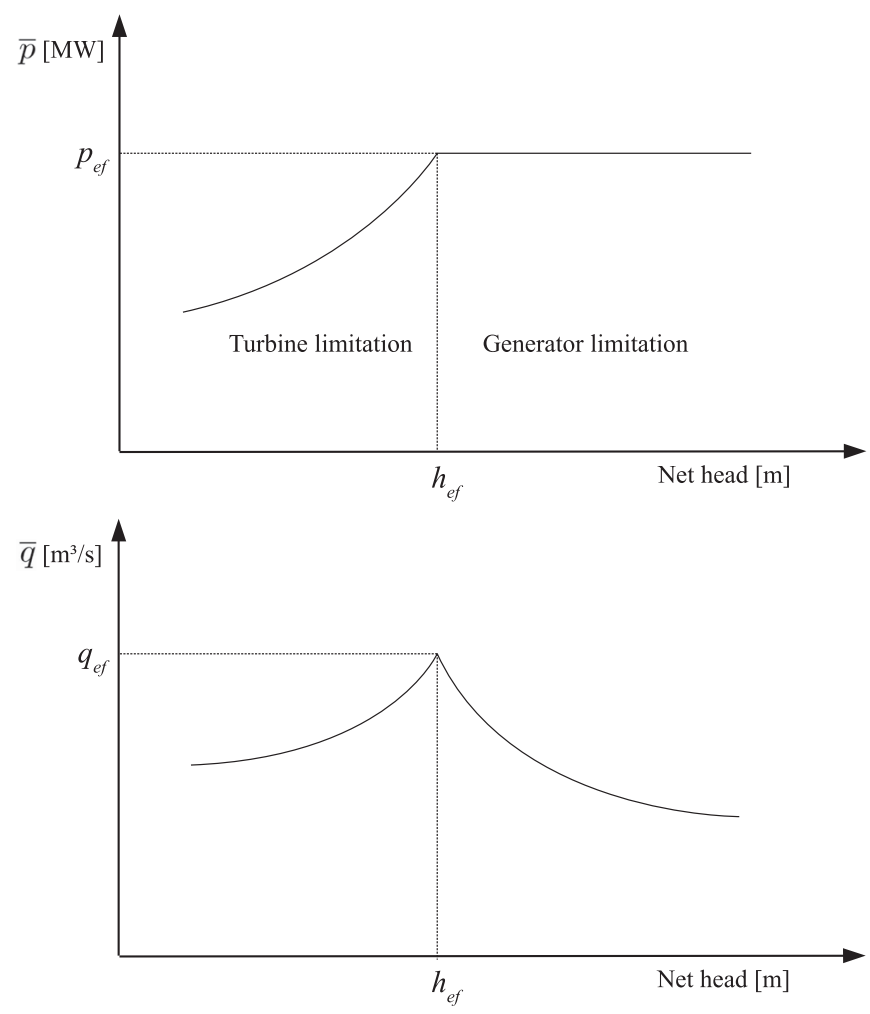

Fig. 1. Maximum power output and water discharge of a generating unit as functions of the net head.

side of the curve these limits are established by the generator. The effective net head $H_{a}^{e f}$ is the minimum net head that produces the maximum power output $P_{a}^{e f}$ and the exact net head that provides the maximum water discharge $Q_{a}^{e f}$.

The limits for maximum power output and the water discharge are given in (19) and (20):

$$
\begin{aligned}
& p_{a}(k) \leq \bar{p}_{a}\left(h_{a}(k)\right), \forall a \in A, \forall k \in K, \\
& q_{a}(k) \leq \bar{q}_{a}\left(h_{a}(k)\right), \forall a \in A, \forall k \in K .
\end{aligned}
$$

Nonlinear and non-differentiability natures of (19) and (20) are inherently represented in the construction of the unit performance curves, as described in Section III-B.

\section{K. Maximum Number of Start-ups}

Maximum number of start-ups of a hydro plant over the time horizon is limited by (21):

$$
\sum_{k \in K} z u_{a}(k) \leq \bar{Z}_{a}, \forall a \in A, \forall k \in K
$$

\section{Network Constraints and Demand}

Nodal balance constraints are formulated as shown in (22):

$$
\begin{array}{r}
\sum_{i:(i, b) \in M_{G}} p_{i}(k)-\sum_{j:(j, b) \in M_{C}} \sum_{n \in N_{j}(k)} p_{n, j}^{D}(k) \\
-\sum_{r:(b, r) \in \Lambda} f_{b, r}(k)=0, \forall k \in K, \forall b \in B,
\end{array}
$$

where $f_{b, r}(k)$ are nonlinear active power flows and accounts for network power losses. Both power flows and losses are linearized as described in Appendix B. Limits in active power flows are as in (23), whereas limits in demand bid blocks are set in (24):

$$
\begin{aligned}
-\bar{F}_{b, r} & \leq f_{b, r}(k) \leq \bar{F}_{b, r}, \forall k \in K, \forall(b, r) \in \Lambda, \\
p_{n, j}^{D}(k) & \leq \bar{P}_{n, j}^{D}(k), \forall n \in N_{j}(k), \forall j \in J, \forall k \in K .
\end{aligned}
$$

\section{Logical Constraints}

The logical constraints are set by (25) and (26). Such constraints are necessary to avoid illogical situations, such as a simultaneous start-up and shut-down of a generating station:

$$
\begin{aligned}
& z u_{i}(k)-z d_{i}(k)= z_{i}(k)-z_{i}(k-1), \\
& \forall i \in I, \forall k \in K, \\
& z u_{i}(k)+z d_{i}(k) \leq 1, \forall i \in I, \forall k \in K .
\end{aligned}
$$

\section{N. Types of Variables}

The constraints (27)-(34) define the nature of the variables:

$$
\begin{aligned}
& z_{i}(k), z u_{i}(k) \in\{0,1\}, \forall i \in I, \forall k \in K, \\
& z d_{i}(k) \in[0,1], \forall i \in I, \forall k \in K, \\
& z p_{a}(k) \in\{0,1\}, \forall a \in A, \forall k \in K, \\
& p_{n, j}^{D}(k) \geq 0, \forall j \in J, \forall k \in K, \forall n \in N, \\
& p_{m, i}^{G}(k) \geq 0, \forall i \in I, \forall k \in K, \forall m \in M, \\
& p_{i}(k), \bar{p}_{i}(k) \geq 0, \forall i \in I, \forall k \in K, \\
& w_{a}^{x, y}(k) \geq 0, \forall a \in A, \forall k \in K, \forall x \in X, \forall y \in Y, \\
& q_{a}(k), \bar{q}_{a}(k), s_{a}(k), u_{a}(k), v_{a}(k), \bar{v}_{a}(k), h u_{a}(k), \\
& \quad h d_{a}(k), h_{a}(k) \geq 0, \forall a \in A, \forall k \in K .
\end{aligned}
$$

The constraints (27) and (29) define the binary variables. Finally, constraints (30)-(34) define non-negative variables. Variables $z p_{a}(k)$ and $w_{a}^{x, y}(k)$ are still to appear in further sections. The linearization techniques are discussed in the following section.

\section{LINEARIZATION TECHNIQUES}

\section{A. Reservoir Fore-bay and Tail-Race Elevations}

In this work, we choose to locally linearize this curve around a base daily operational point by considering daily allowed variations in fore-bay elevations. This linearization is given by constraints (35).

$$
h u_{a}(k)=H U_{a, 0}+H U_{a, 1} \bar{v}_{a}(k), \forall a \in A, \forall k \in K,
$$

where:

$$
\begin{aligned}
H U_{a, 0} & =\frac{\left(\bar{V}_{a}-\underline{V}_{a}\right) \underline{H U}_{a}-\left(\overline{H U}_{a}-\underline{H U}_{a}\right) \underline{V}_{a}}{\bar{V}_{a}-\underline{V}_{a}}, \forall a \in A, \\
H U_{a, 1} & =\frac{\overline{H U}_{a}-\underline{H U}_{a}}{\bar{V}_{a}-\underline{V}_{a}}, \forall a \in A .
\end{aligned}
$$




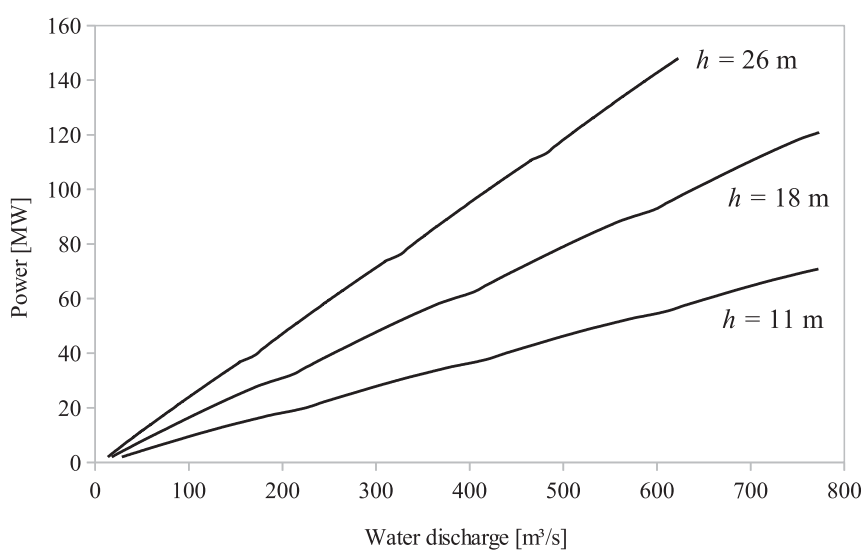

Fig. 2. Performance curves for Barra Bonita plant for 3 net head values.

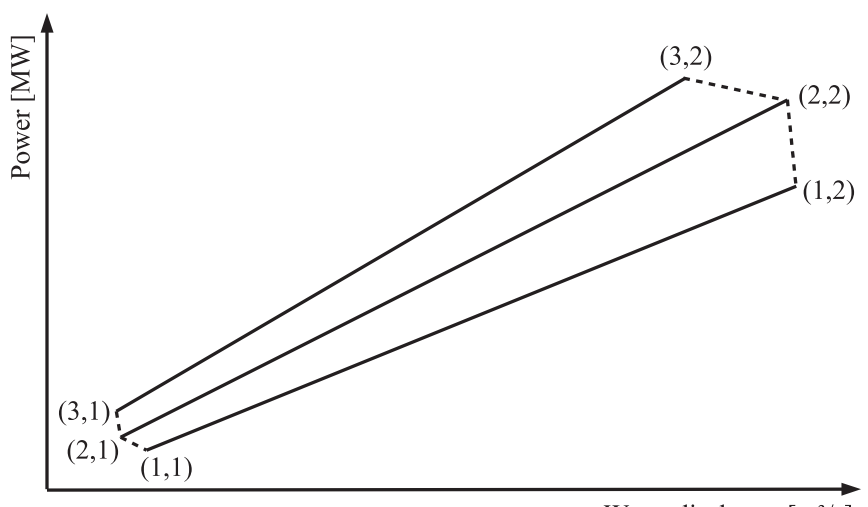

Water discharge $\left[\mathrm{m}^{3} / \mathrm{s}\right]$

Fig. 3. Illustration of the linearization technique used.

For the plants used in the case study presented in this paper, the error obtained through a direct linearization of this curve is small. The linearized tail-race elevation is given in (36):

$$
h d_{a}(k)=H D_{a_{0}}+H D_{a_{1}} u_{a}(k), \forall a \in A, \forall k \in K .
$$

\section{B. Hydroelectric Power Generation Function}

As previously discussed, we constructed performance curves for the hydro plants, rather than for their units. The construction of such curves is analogous to that of unit performance curves, but adopting a previously established unit commitment sequence. This is not an important issue when the plant is composed of similar units (made by the same manufacturing company), however, if the units are not similar, the adoption of specific commitment sequences may result in different plant performance curves. Fig. 2 shows the performance curves for three different net head values of Barra Bonita hydro plant. Note that minimum and maximum operative ranges of the hydro plant vary with the net head.

With the purpose of obtaining a linear representation of the plant performance curves, an interpolation technique is developed based on [3], that uses three linear performance curves, as shown in the Fig. 3, and establishes a three-dimensional interpolation among them. In Fig. 3 six vertexes are denoted by its position $(x, y)$ in the subspace defined by power output and water release. The region formed by the union of these vertexes is divided into two quadrangles. For interpolation purposes, we associate weights $w_{a}^{x, y}(k)$ for each vertex, which are used to compose an interpolation function based on the three reference curves. This technique uses only a single binary variable $z p_{a}(k)$, that defines the quadrangle being used. If the plant operates in the upper quadrangle, then $z p_{a}(k)=1$, and the four upper vertexes are used in the interpolation, otherwise $z p_{a}(k)=0$ and the four lower vertexes are used. This technique allows to calculate operating points (power output, net head and water discharge) which are located in intermediate regions of the three reference curves.

The constraints (37)-(44) represent the hydro generation function by the interpolation technique used:

$$
\begin{aligned}
& \sum_{x \in X} \sum_{y \in Y} w_{a}^{x, y}(k)=z_{a}(k), \forall a \in A, \forall k \in K, \\
& h_{a}(k) \leq \sum_{x \in X} \sum_{y \in Y} w_{a}^{x, y}(k) H_{a}^{x, y}+H_{a}^{3,1}\left[1-z_{a}(k)\right], \\
& \forall a \in A, \forall k \in K, \\
& h_{a}(k) \geq \sum_{x \in X} \sum_{y \in Y} w_{a}^{x, y}(k) H_{a}^{x, y}, \forall a \in A, \forall k \in K, \\
& q_{a}(k)=\sum_{x \in X} \sum_{y \in Y} w_{a}^{x, y}(k) Q_{a}^{x, y}, \forall a \in A, \forall k \in K, \\
& p_{a}(k)=\sum_{x \in X} \sum_{y \in Y} w_{a}^{x, y}(k) P_{a}^{x, y}, \forall a \in A, \forall k \in K, \\
& w_{a}^{2,1}(k)+w_{a}^{2,2}(k) \leq 1, \forall a \in A, \forall k \in K, \\
& w_{a}^{1,1}(k)+w_{a}^{1,2}(k) \leq 1-z p_{a}(k), \forall a \in A, \forall k \in K, \\
& w_{a}^{3,1}(k)+w_{a}^{3,2}(k) \leq z p_{a}(k), \forall a \in A, \forall k \in K .
\end{aligned}
$$

Constraints (37) relate the vertexes weights and the on/off states of the plant. If the plant is off, the sum of the weights is zero, disabling all constraints associated with the interpolation. Constraints (38) and (39) calculate the interpolated net head value. If the plant is on, they represent an equality constraint that defines the net head. If the plant is off, such constraints are disabled, by allowing the net head to assume any value between zero and $H_{a}^{3,1}$ (maximum allowed value). Constraints (40) and (41) interpolate water discharge and power output values, respectively. If the plant is off, these two variables are null. Constraints (42)-(44) select the vertexes used in the interpolation. If the net head value is between $2^{\text {nd }}$ and the $3^{\text {rd }}$ curves, then $z p_{a}(k)=1$ and the points for $1^{\text {st }}$ curve have null weight because $w_{a}^{1,1}(k)+w_{a}^{1,2}(k) \leq 0$. Analogously, if the net head value is between the $1^{\text {st }}$ and the $2^{\text {nd }}$ curves, $z p_{a}(k)=0$ and the points on the $3^{\text {rd }}$ curve have null weight because $w_{a}^{3,1}(k)+w_{a}^{3,2}(k) \leq 0$. If the plant is on, the points of $2^{\text {nd }}$ curve always have nonzero weights because this curve will always be part of the interest region (upper or lower).

The main advantages of the interpolation technique are: i) only one binary variable is used for each power plant; ii) good accuracy when interpolated values are compared to real 
values, as discussed in [3] and shown in the Results section; iii) all non-convexities embedded in the performance curve, such as the influence of net heads in the operation of hydro plants are represented.

Limits in net head, water discharge and power output are inherently represented in the plant performance curves. Therefore, we do not need to insert such limits as constraints in the problem formulation. Moreover, there is no need to limit the fore-bay and tail-race elevations, since these variables are functions of the water release and the reservoir volume, respectively, which are limited by the constraints (6) and (9), respectively.

\section{Mixed-Integer Linear Mathematical Formulation}

In this section we summarize the proposed NetworkConstrained Market Clearing Procedure (NCMCP) model, from (45) to (53):

$$
\text { Maximize (1) }
$$

Subject to:

$$
\begin{aligned}
& (2)-(4) \\
& (5)-(14),(21) \\
& (17),(35)-(36) \\
& (37)-(44) \\
& (55)-(63) \\
& (22)-(24) \\
& (64)-(65),(67)-(72) \\
& (25)-(34) .
\end{aligned}
$$

The constraints (46) enforce power output limits and power block limits for both thermal units and hydro plants. Hydraulic constraints are enforced by (47)-(49); (47) are inherently linear hydro constraints, while (48) represents the linearization of the head functions and (49) represents the linearization of the hydro production function. Constraints associated with thermal generating units are enforced by (50). Network constraints are enforced by (51) and (52), where (52) are used to linearize network power losses. Constraints (53) describe logical relations among binary variables and types of variables.

\section{NumERICAL RESUlTS AND DisCUSSIONS}

Numerical results presented in this section focus on the evaluation of the following aspects concerning the NCMCP model: i) impact of hydraulic constraints in market clearing prices and scheduling (Section V-B); ii) impact of strategic bidding of hydro plants on hydraulic operation of cascades (Section V-C); and iii) impact of transmission system losses and congestion in market clearing prices (Section V-D). A small test-system

\begin{tabular}{|c|c|c|c|c|c|}
\hline \multirow{2}{*}{$\begin{array}{l}\text { Gen. } \\
\text { station }\end{array}$} & \multicolumn{4}{|c|}{ Quantity [MW] / Price [\$/MWh] } & \multirow{2}{*}{$\begin{array}{l}\text { Start-up } \\
\text { offer [\$] }\end{array}$} \\
\hline & Block 1 & Block 2 & Block 3 & Block 4 & \\
\hline 1 & $25 / 17.81$ & $15 / 17.98$ & $10 / 18.05$ & $0 / 0$ & 0 \\
\hline 2 & $90 / 16.99$ & $50 / 17.11$ & $40 / 17.14$ & $30 / 17.69$ & 0 \\
\hline 3 & $1000 / 15.91$ & $150 / 16.05$ & $100 / 16.11$ & $50 / 16.59$ & 0 \\
\hline 4 & $200 / 16.19$ & $180 / 16.45$ & $100 / 16.51$ & $25 / 16.98$ & 0 \\
\hline 5 & $600 / 15.77$ & $200 / 15.91$ & $150 / 15.98$ & $80 / 16.44$ & 0 \\
\hline 6 & $300 / 16.54$ & $80 / 16.69$ & $50 / 16.76$ & $40 / 17.14$ & 0 \\
\hline 7 & $50 / 18.13$ & $15 / 18.30$ & $10 / 18.37$ & $5 / 18.87$ & 0 \\
\hline 8 & $60 / 18.75$ & $40 / 18.91$ & $20 / 18.99$ & $5 / 19.51$ & 0 \\
\hline 9 & $850 / 17.31$ & $180 / 17.47$ & $150 / 17.54$ & $70 / 18.03$ & 0 \\
\hline 10 & $1070 / 14.86$ & $300 / 15.00$ & $100 / 15.06$ & $20 / 15.51$ & 0 \\
\hline 11 & $20 / 27.22$ & $30 / 27.82$ & $35 / 29.32$ & $45 / 30.20$ & 2200 \\
\hline 12 & $20 / 26.95$ & $25 / 27.54$ & $37 / 29.03$ & $48 / 29.90$ & 2200 \\
\hline 13 & $100 / 28.30$ & $120 / 28.92$ & $120 / 30.48$ & $120 / 31.39$ & 20500 \\
\hline 14 & $50 / 27.73$ & $100 / 28.34$ & $120 / 29.87$ & $30 / 30.77$ & 10300 \\
\hline
\end{tabular}
used in Sections V-B and V-C is presented in Section V-A. In Section V-D, we work with the IEEE reliability test-system [24] and evaluate the overall computational burden of the proposed NCMCP model.

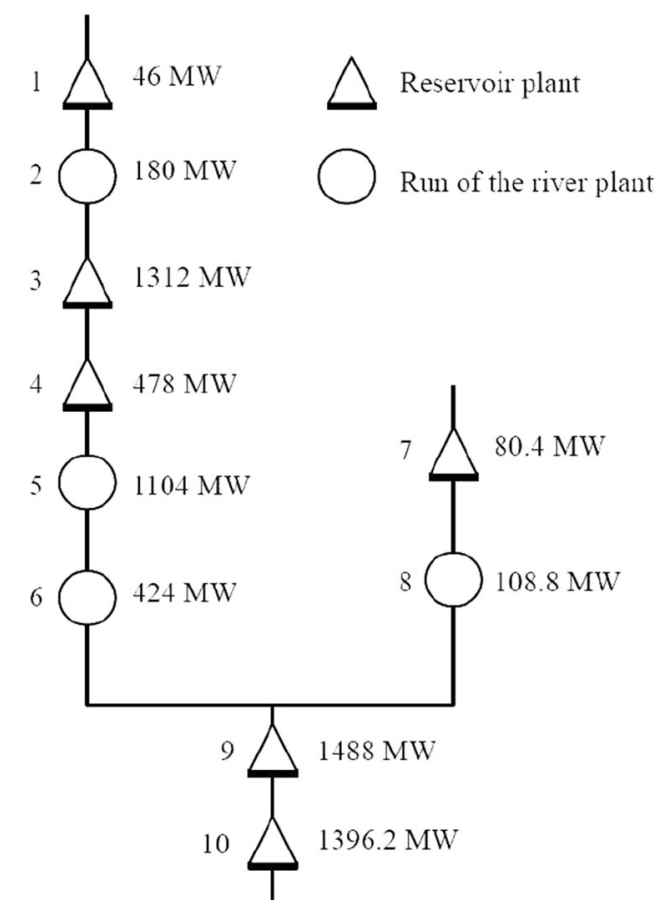

Fig. 4. Hydraulic cascade studied.

TABLE I

STRUCTURE OF SELLING ENERGy OFFERS—CASES A AND B

\section{A. Small Test-System Data}

The proposed NCMCP model was tested for a system comprising a hydraulic cascade based on Brazilian hydroelectric plants, with 10 hydro plants (6 reservoir plants and 4 run-ofthe-river plants) shown in Fig. 4, and four thermal units (units $1,2,3$ and 12 described in [1], here renumbered from 11 to 14). We simulated a dry season for this system so as to emphasize the influence of the hydraulic constraints in the outcomes of the proposed model.

Offers and bids are given in Tables I and II, respectively. For simplicity, a single consumer was considered. Furthermore, offers were regarded as constant throughout the day. Indexes from 1 to 10 represent hydro plants while indexes from 11 to 14 represent thermal units.

Table III shows the number of constraints and variables (real and binary) and runtime required to attain the optimal solution of the case studies. The model was run on a Intel Core i7 processor, 
TABLE II

STRUCTURE OF BUYING ENERGY BIDS-CASES A-D

\begin{tabular}{|c|c|c|c|c|}
\hline \multirow{2}{*}{ Hour } & \multicolumn{4}{|c|}{ Quantity [MW] / Price [\$/MWh] } \\
\cline { 2 - 5 } & Block 1 & Block 2 & Block 3 & Block 4 \\
\hline 1 & $3156 / 29.98$ & $664 / 28.70$ & $332 / 26.76$ & $166 / 25.55$ \\
2 & $3303 / 29.14$ & $709 / 28.85$ & $354 / 28.00$ & $177 / 26.68$ \\
3 & $3401 / 30.31$ & $739 / 29.04$ & $369 / 28.18$ & $185 / 26.84$ \\
4 & $3451 / 38.37$ & $754 / 29.07$ & $377 / 28.21$ & $189 / 26.87$ \\
5 & $3529 / 30.69$ & $1086 / 29.38$ & $543 / 28.50$ & $271 / 26.14$ \\
6 & $4921 / 31.18$ & $1206 / 29.85$ & $603 / 28.94$ & $302 / 26.55$ \\
7 & $5166 / 31.45$ & $1282 / 29.98$ & $641 / 29.06$ & $320 / 26.66$ \\
8 & $5656 / 31.45$ & $1433 / 29.98$ & $716 / 29.06$ & $358 / 26.66$ \\
9 & $4921 / 31.18$ & $1206 / 29.85$ & $603 / 28.94$ & $302 / 26.55$ \\
10 & $4676 / 30.69$ & $1131 / 29.38$ & $566 / 28.50$ & $283 / 26.14$ \\
11 & $5852 / 31.45$ & $1493 / 29.98$ & $746 / 29.06$ & $373 / 26.66$ \\
12 & $5901 / 31.62$ & $1508 / 30.14$ & $754 / 29.21$ & $377 / 26.80$ \\
13 & $5852 / 31.62$ & $1493 / 30.14$ & $746 / 29.21$ & $373 / 26.80$ \\
14 & $5019 / 31.29$ & $1237 / 29.85$ & $618 / 28.94$ & $309 / 26.55$ \\
15 & $4970 / 31.29$ & $1221 / 29.85$ & $611 / 28.94$ & $305 / 26.55$ \\
16 & $4676 / 29.98$ & $1131 / 29.58$ & $566 / 28.74$ & $283 / 26.44$ \\
17 & $5117 / 30.04$ & $1267 / 29.64$ & $633 / 28.80$ & $317 / 26.50$ \\
18 & $5803 / 31.29$ & $1478 / 29.85$ & $739 / 28.94$ & $369 / 26.55$ \\
19 & $5911 / 31.62$ & $1508 / 30.14$ & $754 / 29.21$ & $377 / 26.80$ \\
20 & $5509 / 30.26$ & $1387 / 29.86$ & $694 / 28.01$ & $347 / 26.68$ \\
21 & $5558 / 29.29$ & $1402 / 28.93$ & $701 / 28.14$ & $351 / 25.88$ \\
22 & $5264 / 29.86$ & $1312 / 28.51$ & $656 / 26.74$ & $328 / 25.52$ \\
23 & $4529 / 29.09$ & $1086 / 28.77$ & $543 / 26.05$ & $271 / 25.88$ \\
24 & $3843 / 29.09$ & $875 / 28.77$ & $437 / 26.05$ & $219 / 25.88$
\end{tabular}

TABLE III

Computational Dimension of THE StUdied CASES

\begin{tabular}{|c|c|c|c|c}
\hline Case & \# Constraints & \# Binary variables & \# Real variables & Time [s] \\
\hline A & 9054 & 912 & 5642 & 8.29 \\
B & 3784 & 672 & 2281 & 0.32 \\
C & 9054 & 912 & 5642 & 5.81 \\
D & 9054 & 912 & 5642 & 6.73 \\
\hline
\end{tabular}

3.60 GHz and $16 \mathrm{~GB}$ of RAM. The CPLEX solver under the GAMS platform [25] was used to solve the problem.

\section{B. Impact of Hydraulic Constraints}

In this section two cases are compared in order to analyze the impact of hydraulic constraints on market clearing prices as well as on generation and consumption scheduling. For such a purpose, in cases $\mathrm{A}$ and $\mathrm{B}$ we neglect the transmission constraints (51) and (52), and introduce the additional set of constraints (54) account for the overall demand-supply equilibrium:

$$
\sum_{i \in I} p_{i}(k)=\sum_{j \in J} \sum_{n \in N_{j}(k)} p_{n, j}^{D}(k), \forall k \in K .
$$

1) Case A: proposed NCMCP model without network constraints (51) and (52);

2) Case B: hydraulic constraints (47)-(49) are neglected in the proposed NCMCP.

Hydro and thermal generation scheduling for Case A is given on Table IV. As expected, thermal generating units have lower participation in the demand supply, due to their higher offer values. Figs. 5 and 6 compare the scheduling for hydro plants and thermal units, respectively, for cases A and B. Note that hydro generation is artificially higher in Case B, due to the absence of the hydraulic constraints. Due to the reduced supply of hydro generation, we may notice an increasing thermal generation in Case A, so as to supply the elastic demand.
TABLE IV

Hydro AND THERMAL GENERATION SCHEDULING FOR CASE A [MW]

\begin{tabular}{|c|cccccccccccccc|}
\hline \multirow{2}{*}{ Hour } & \multicolumn{10}{|c}{ Generating station } \\
\cline { 2 - 7 } & 1 & 2 & 3 & 4 & 5 & 6 & 7 & 8 & 9 & 10 & 11 & 12 & 13 & 14 \\
\hline 1 & 50 & 0 & 1017 & 302 & 600 & 300 & 0 & 0 & 850 & 1109 & 20 & 20 & 0 & 50 \\
2 & 50 & 0 & 1094 & 299 & 636 & 300 & 0 & 0 & 850 & 1224 & 20 & 20 & 0 & 50 \\
3 & 50 & 0 & 1150 & 298 & 690 & 300 & 0 & 0 & 850 & 1266 & 20 & 20 & 0 & 50 \\
4 & 50 & 0 & 1217 & 299 & 606 & 300 & 0 & 0 & 902 & 1308 & 20 & 20 & 0 & 50 \\
5 & 50 & 0 & 1300 & 324 & 861 & 449 & 50 & 112 & 954 & 1350 & 20 & 20 & 0 & 50 \\
6 & 50 & 0 & 1300 & 325 & 937 & 470 & 72 & 112 & 1048 & 1358 & 85 & 82 & 0 & 150 \\
7 & 50 & 108 & 1300 & 327 & 1012 & 470 & 72 & 112 & 1046 & 1358 & 85 & 130 & 0 & 270 \\
8 & 50 & 150 & 1300 & 330 & 1030 & 470 & 72 & 111 & 1044 & 1357 & 85 & 130 & 0 & 270 \\
9 & 50 & 114 & 1300 & 332 & 1030 & 470 & 72 & 111 & 1043 & 1357 & 50 & 47 & 0 & 150 \\
10 & 50 & 90 & 1300 & 334 & 1030 & 470 & 72 & 110 & 1042 & 1357 & 50 & 45 & 0 & 150 \\
11 & 50 & 194 & 1300 & 336 & 1030 & 470 & 72 & 110 & 1041 & 1357 & 85 & 130 & 0 & 270 \\
12 & 50 & 194 & 1300 & 338 & 1030 & 470 & 72 & 109 & 1040 & 1357 & 85 & 130 & 0 & 270 \\
13 & 50 & 194 & 1300 & 338 & 1030 & 470 & 72 & 109 & 1039 & 1357 & 85 & 130 & 0 & 270 \\
14 & 50 & 180 & 1300 & 338 & 1030 & 470 & 72 & 109 & 1038 & 1357 & 80 & 82 & 0 & 150 \\
15 & 50 & 180 & 1300 & 338 & 1030 & 470 & 72 & 109 & 1037 & 1357 & 50 & 48 & 0 & 150 \\
16 & 50 & 90 & 1300 & 338 & 1030 & 470 & 72 & 108 & 1036 & 1357 & 50 & 45 & 0 & 150 \\
17 & 50 & 194 & 1300 & 338 & 1030 & 470 & 72 & 108 & 1035 & 1357 & 85 & 82 & 0 & 150 \\
18 & 50 & 194 & 1300 & 338 & 1030 & 470 & 72 & 107 & 1035 & 1357 & 85 & 82 & 0 & 150 \\
19 & 50 & 194 & 1300 & 338 & 1030 & 470 & 72 & 107 & 1034 & 1357 & 85 & 130 & 0 & 270 \\
20 & 50 & 194 & 1300 & 338 & 1030 & 470 & 72 & 106 & 1033 & 1357 & 85 & 82 & 0 & 150 \\
21 & 50 & 180 & 1300 & 338 & 1030 & 470 & 72 & 106 & 1032 & 1357 & 50 & 45 & 0 & 150 \\
22 & 50 & 172 & 1300 & 342 & 1030 & 470 & 72 & 106 & 1032 & 1357 & 50 & 45 & 0 & 150 \\
23 & 50 & 171 & 1300 & 342 & 1030 & 470 & 72 & 105 & 1031 & 1357 & 0 & 0 & 0 & 0 \\
24 & 25 & 0 & 1300 & 343 & 953 & 460 & 0 & 0 & 935 & 1357 & 0 & 0 & 0 & 0 \\
\hline
\end{tabular}

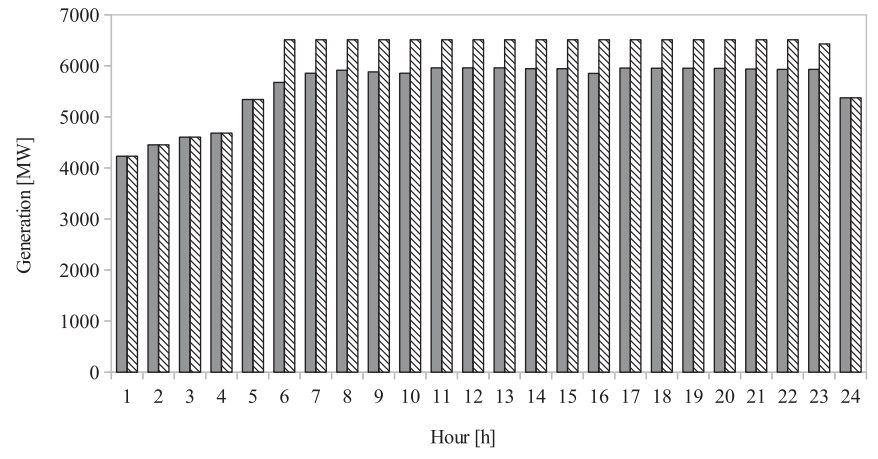

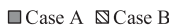

Fig. 5. Total hydro generation for cases A and B.

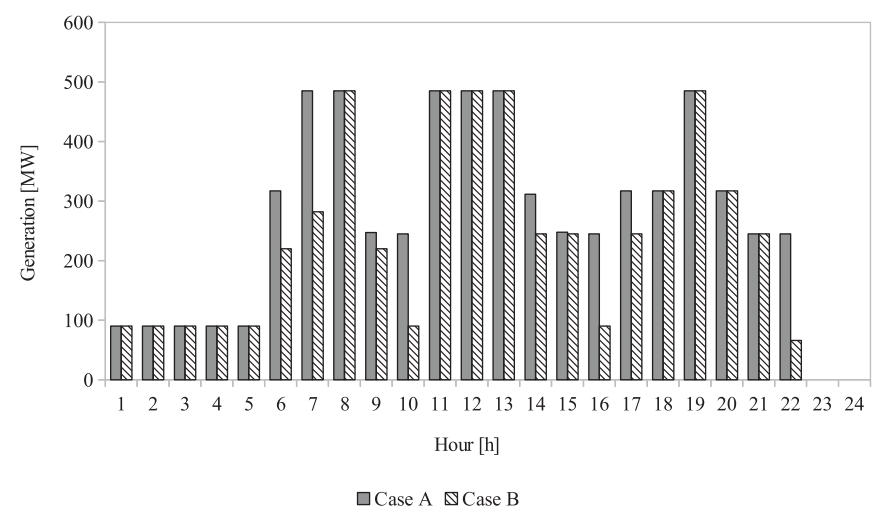

Fig. 6. Total thermal generation for cases A and B.

The values obtained for the objective function in cases A and B were \$ 1943767.99 and \$ 2081613.98, respectively. We may verify an artificial increase in the social welfare function from Case A to Case B. This is justified by the increase in cheaper 


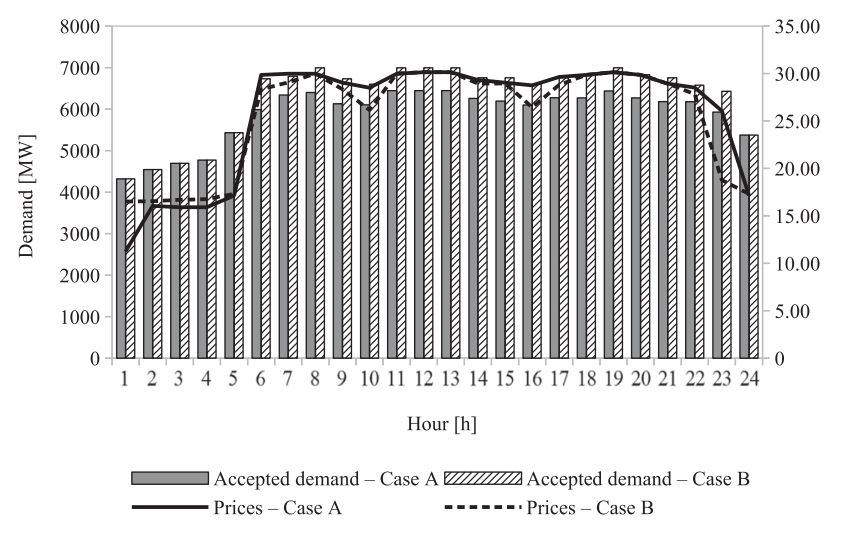

Fig. 7. Evolution of hourly market clearing prices and demand.

TABLE V

AVERAGE INTERPOLATION ERRORS FOR THE NONLINEAR PERFORMANCE CURVES OF HYDRO PLANTS

\begin{tabular}{|c|c|c|}
\hline Hydro Plant & Error [\%] & Standard Deviation [\%] \\
\hline 1 & 0.57100 & 0.42722 \\
2 & 0.91013 & 1.04572 \\
3 & 1.34855 & 1.10742 \\
4 & 0.29925 & 0.14688 \\
5 & 0.09770 & 0.06136 \\
6 & 0.56104 & 0.28307 \\
7 & 0.55900 & 0.05319 \\
8 & 0.26124 & 0.20525 \\
9 & 0.94479 & 0.35324 \\
10 & 0.38639 & 0.66728 \\
\hline
\end{tabular}

hydroelectric generation, thereby increasing the production and consumption surpluses in (1).

Fig. 7 shows the hourly market clearing prices and the accepted demand for Cases A and B. We observe that in both cases, prices tend to follow the demand curve, as expected. It is noticeable that the hydraulic constraints have a significant impact on prices. In most periods of the day, prices are artificially lower for Case B. In Case A, when hydraulic constraints are effectively introduced, and due to the drought situation in which water becomes scarce, energy prices raise. Moreover, we may note a decrease in the accepted demand bids for Case A. This occurs because hydro constraints tend to decrease the supply of hydro generation, therefore, thermal units may have the opportunity to increase their generation. However, thermal generation is more expensive and it is not always accepted by the elastic demand.

In order to verify the errors of the linearization technique for the performance curves adopted, we compare the optimal power output values calculated by the model proposed in all periods, and for all plants, with the ones calculated using the "real" nonlinear hydroelectric power generation function, described in Section II-I of the paper. The interpolation errors obtained by such comparison are listed in Table $\mathrm{V}$ for each hydro plant.

We observe in Table $\mathrm{V}$ that average errors are within acceptable bounds (most are below 1\%) and the corresponding values of standard deviation show that the dispersion for the set of data values used (we worked with 209 operational points) is also small.
TABLE VI

Structure of OfFer Block Prices-Cases C ANd D

\begin{tabular}{|c|c|c|c|c|}
\hline \multirow{2}{*}{$\begin{array}{c}\text { Hydro } \\
\text { plant }\end{array}$} & \multicolumn{3}{|c|}{ Offer block Prices - Case C / Case D [\$/MWh] } \\
\cline { 2 - 5 } & Block 1 & Block 2 & Block 3 & Block 4 \\
\hline 1 & $11.81 / 21.75$ & $11.98 / 21.91$ & $12.05 / 21.99$ & $0 / 0$ \\
2 & $12.49 / 19.48$ & $12.54 / 19.51$ & $12.69 / 19.69$ & $12.79 / 20.31$ \\
3 & $14.12 / 17.25$ & $14.25 / 17.31$ & $14.41 / 17.59$ & $14.89 / 17.61$ \\
4 & $15.29 / 17.65$ & $15.45 / 17.81$ & $15.51 / 17.99$ & $15.98 / 18.21$ \\
5 & $17.77 / 16.45$ & $17.91 / 16.51$ & $17.98 / 16.69$ & $18.14 / 16.71$ \\
6 & $18.34 / 15.25$ & $18.79 / 15.31$ & $18.96 / 15.49$ & $19.24 / 15.81$ \\
7 & $11.13 / 21.75$ & $11.30 / 21.91$ & $11.37 / 21.99$ & $11.87 / 22.51$ \\
8 & $12.75 / 18.08$ & $12.91 / 18.11$ & $12.99 / 18.39$ & $13.51 / 19.51$ \\
9 & $19.31 / 13.13$ & $19.47 / 13.30$ & $19.54 / 13.37$ & $20.03 / 13.48$ \\
10 & $21.31 / 11.81$ & $21.47 / 11.98$ & $21.54 / 12.05$ & $22.03 / 12.11$ \\
\hline
\end{tabular}

TABLE VII

Daily Spillage and Water Discharge Volumes for Cases C AND D

\begin{tabular}{|c|cc|cc|cc}
\hline $\begin{array}{c}\text { Hydro } \\
\text { plant }\end{array}$ & \multicolumn{2}{|c|}{ Water discharge vol. $\left[\mathrm{hm}^{3}\right.$ ] } & \multicolumn{2}{|c|}{ Spillage vol. $\left[\mathrm{hm}^{3}\right.$ ] } & \multicolumn{2}{|c}{ Energy [MWh] } \\
\hline 1 & 37.64 & $\mathrm{D}$ & $\mathrm{C}$ & $\mathrm{D}$ & $\mathrm{C}$ & $\mathrm{D}$ \\
\hline 2 & 29.75 & 28.48 & 5.76 & 5.76 & 1200 & 1134 \\
3 & 169.01 & 165.15 & 8.64 & 9.27 & 2964 & 2790 \\
4 & 122.31 & 121.34 & 2.15 & 7.26 & 30735 & 30032 \\
5 & 149.21 & 150.36 & 2.64 & 2.58 & 7942 & 7828 \\
6 & 93.83 & 95.57 & 20.32 & 1.16 & 22507 & 22585 \\
7 & 8.72 & 6.58 & 1.3 & 3.09 & 10430 & 10620 \\
8 & 11.9 & 10.24 & 0.05 & 0.70 & 2301 & 1987 \\
9 & 231.72 & 237.45 & 1.68 & 0.64 & 24042 & 24548 \\
10 & 239.01 & 246.39 & 1.7 & 0.36 & 31226 & 32214 \\
\hline
\end{tabular}

\section{Impact of Strategic Offering on the Hydraulic Operation of Cascades}

In this section, cases $\mathrm{C}$ and $\mathrm{D}$ are compared in order to analyze the impact of the strategic offering of the hydro plants on the operation of the cascade. Therefore, in these cases, we also neglect transmission constraints (51)-(52) and introduce the additional set of constraints (54) to account for the overall demand-supply equilibrium.

1) Case C: The proposed NCMCP model is solved considering that plants $1-4,7$ and 8 provide lower offer block prices in the auction when compared to Case D. Therefore, the offer block prices are set in an ascending order from upstream to downstream in the cascade.

2) Case D: The proposed NCMCP model is solved considering that plants 5, 6, 9 and 10 provide lower offer block prices in the auction in relation to the Case C. Thus, offer block prices are set in descending order from upstream to downstream in the cascade.

The structure of the offer block prices for cases C and D is shown in Table VI.

The hydraulic operation of the cascade is evaluated by calculating the total daily volumes associated with water discharges and spillages of each plant, in each case studied, and checking how such hydraulic variables are affected by the different strategies of offer prices for cases $\mathrm{C}$ and $\mathrm{D}$.

Table VII shows total daily volumes associated with water discharge and spillage, and daily energy produced by hydro plants. The upstream plants $1-4,7$ and 8 , which increased their offer prices from case $\mathrm{C}$ to $\mathrm{D}$, experience a reduction in their total daily energy, and as a consequence, these plants also reduce their water discharge volumes. This occurs because consumers tend to buy energy at lower prices in the auction, as expected. 
The opposite occurs in the downstream plants, 5, 6, 9 and 10, which decrease their offer prices from case $C$ to $D$. These plants experience an increase in their daily energy produced and in water discharge volumes.

It is also noticeable from Table VII that the upstream plants increase their daily spillage volumes from case $\mathrm{C}$ to $\mathrm{D}$. The explanation for that lies in the offer block structure: the upstream plants (with higher offer prices) transfer water volumes to the downstream plants (with lower offer prices) by increasing their spillage volumes. This mechanism relocates water/energy from the most expensive plants (upstream) to the cheapest ones (downstream). In summary, the spillage from upstream plants, has the purpose to transfer water/energy to the downstream plants in order to generate more energy in cheaper plants. The results described in Table VII show that the operation of a hydraulic cascade can be significantly affected by the offer prices provided by hydroelectric plants in the cascade. We may say that the operation of the hydraulic cascade is guided by the offer prices.

We notice that if upstream and downstream plants are owned by different generation companies, a company may have to transfer water from its own reservoirs to the reservoirs of other companies, so that they may generate more energy. This practice could face some resistance from the generation companies. On the other hand, once water is a public good it must be used to generate energy as efficiently as possible. It is also important to consider that the decision to generate more or less energy in a given plant is not imposed by the system operator, it is the result of a competitive offer price structure in the auction. Thus, if a company is willing to generate more energy, it should provide more competitive prices in the auction.

We observe that in this type of operation the ISO accumulates additional functions, since he also has to coordinate the operation of hydraulic cascades in hydropower systems. Since the ISO is the entity responsible for ensuring system security and reliability, which are closely linked to hydro availability in hydropower systems, it is reasonable that he also becomes responsible for coordinating the hydraulic operation.

Finally, we analyze the values obtained for the objective function in cases C and D, which were \$ 1793993.01 and $\$ 2067444.03$, respectively. Note that in the case C, the hydroelectric plants with lower prices (the most upstream plants in the cascade) are also those with lower installed capacity. This reduced capacity causes a reduction in the production surplus reducing social welfare, as expected.

\section{Impact of the Transmission System Representation}

In order to analyze the impact of the transmission system representation on the market clearing prices and on the overall computational burden for solving the NCMCP model, we adapted the IEEE reliability test-systems with 24,48 and 73 buses (we used the systems in [24] for the instance provided in Appendix B of [26]) respectively, by replacing most thermal units by hydraulically coupled hydro plants with similar power capacity. Data for the hydro plants were extracted from the Brazilian system [17]. The generating stations were connected
TABLE VIII

MAPPING OF THE GENERATING STATIONS INTO THE GRID

\begin{tabular}{|c|cccccccc}
\hline Gen. station & 1 & 2 & 3 & 4 & 5 & 6 & 7 & 8 \\
Bus & 118 & 118 & 116 & 115 & 115 & 101 & 121 & 121 \\
\hline Gen. station & 9 & 10 & 11 & 12 & 13 & 14 & 15 & \\
Bus & 122 & 113 & 113 & 107 & 102 & 123 & 123 & \\
\hline
\end{tabular}

TABLE IX

EVALUATION OF THE COMPUTATIONAL BURDEN ASSOCIATED WITH NETWORK AND HYDRAULIC CONSTRAINTS

\begin{tabular}{|c|c|c|c|c|c|c|c|}
\hline Case & Syst. & $\begin{array}{c}\text { Obj } \\
\text { Fun.[\$] }\end{array}$ & $\begin{array}{c}\text { Time } \\
{[\mathrm{s}]}\end{array}$ & \# Const. & $\begin{array}{c}\text { \# Real } \\
\text { Var. }\end{array}$ & $\begin{array}{c}\text { \# Bin. } \\
\text { Var. }\end{array}$ & $\begin{array}{l}\text { Gap } \\
{[\%]}\end{array}$ \\
\hline \multirow{3}{*}{ E } & 24-Bus & 949912.4 & 0.35 & 5588 & 4249 & 720 & 0 \\
\hline & 48-Bus & 1344505.3 & 0.55 & 11152 & 8497 & 1440 & 0 \\
\hline & 73-Bus & 2401303.4 & 0.61 & 16716 & 12745 & 2160 & 0 \\
\hline \multirow{3}{*}{$\mathrm{F}$} & 24-Bus & 930438.9 & 22.25 & 12439 & 8617 & 1032 & 0 \\
\hline & 48-Bus & 1201259.4 & 56.26 & 24854 & 17233 & 2064 & 0 \\
\hline & 73-Bus & 2176742.6 & 1800 & 37269 & 25849 & 3096 & 0.07 \\
\hline \multirow{3}{*}{ G } & 24-Bus & 930797.9 & 0.81 & 20852 & 16249 & 720 & 0 \\
\hline & 48-Bus & 1197170.6 & 3.35 & 42976 & 33505 & 1440 & 0 \\
\hline & 73-Bus & 2206915.3 & 5.21 & 65124 & 50785 & 2160 & 0 \\
\hline \multirow{3}{*}{$\mathrm{H}$} & 24-Bus & 903390.5 & 405.2 & 27703 & 20617 & 1032 & 0 \\
\hline & 48-Bus & 1123282.1 & 620.25 & 56678 & 42241 & 2064 & 0 \\
\hline & 73-Bus & 2031945.3 & 1800 & 85677 & 63889 & 3096 & 0.16 \\
\hline
\end{tabular}

to the grid as described in Table VIII, where the first 13 generating stations are hydro plants, while the remaining two are thermal units. These data are doubled and tripled, respectively, for the 48- and 73-bus systems.

Evaluation concerning the computational burden associated with network and hydraulic constraints are synthesized in Table IX, for 4 different case studies:

1) Case E: network constraints (51) and (52) as well as hydraulic constraints (47)-(49) are neglected in the proposed NCMCP. The additional set of constraints (54) is introduced to represent the overall demand-supply equilibrium;

2) Case F: network constraints (51) and (52) are neglected in the proposed NCMCP. The additional set of constraints (54) is introduced to represent the overall demand-supply equilibrium;

3) Case G: hydraulic constraints (47)-(49) are neglected in the proposed NCMCP;

4) Case H: complete proposed NCMCP model.

Note in Table IX that for Cases $\mathrm{F}$ and $\mathrm{H}$ involving the 73-bus system, the execution was terminated after $30 \mathrm{~min}$, with a nonnull final gap. This occurred because the branch-and-bound tree has not been totally explored, however the results are very close to the optimal.

By comparing Cases $\mathrm{E}$ and $\mathrm{G}$, we may assess the impact of network constraints on the computational time for solving the problem. Computational times for Case $\mathrm{G}$ are greater than the ones obtained for Case E, as expected. By comparing Cases E and F, we may assess the impact of hydraulic constraints on the computational time, which is substantially greater than the impact of network constraints for this instance of the problem. The computational burden for the complete NCMCP model (Case $\mathrm{H})$, which involves a huge number of constraints and variables, is the greatest, as expected.

To evaluate the impact of the transmission system in market clearing prices we worked with the complete NCMCP model (Case $\mathrm{H}$ ) and solved the 73-bus system, which is divided in three 


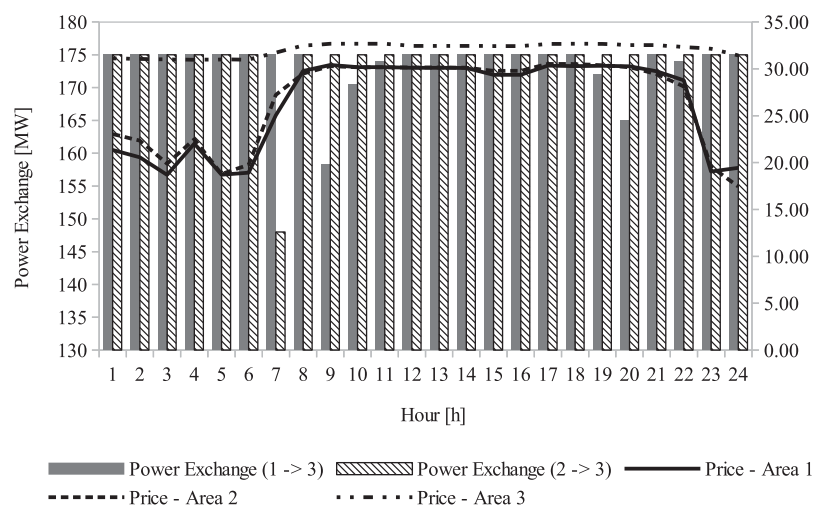

Fig. 8. Average market clearing prices and power exchanges among areas obtained for the 73-bus system.

subnetworks (Areas 1, 2 and 3). We explored a situation in which Areas 1 and 2 are facing a wet season, while area 3 is facing a drought. For simulating such situation we introduced high values of water inflow data for the reservoirs in Areas 1 and 2 and low values of water inflow data for reservoirs in Area 3. We made the same with initial volumes in the reservoirs of such areas. Due to the abundance of water in Areas 1 and 2, we adopted small offerblock prices for the hydro plants in these areas, and higher offerblock prices for the hydro plants in Area 3, reflecting the higher water value in this area, associated with the drought. Average market clearing prices and power exchanges among areas for each period, calculated by the proposed NCMCP model, are shown in Fig. 8.

We notice that average market clearing prices are higher in Area 3 because of the drought which leads to higher offer-block prices in this area. Note that power exchanges among areas are on their maximum values (175 MW) in almost all periods and that these flows are oriented from Areas 1 and 2 (with lower prices) to Area 3 (with higher prices), in an attempt to equalize prices among areas (in accordance with power system economics) [27].

Therefore, the differences in average market clearing prices among the areas, shown in Fig. 8, are associated with the network congestion (in the tie-lines) and losses. In order to corroborate this result, we artificially eliminate the network congestion by setting maximum power limits in the tie-lines to $400 \mathrm{MW}$. The new values for average market clearing prices and power exchanges for each period, calculated by the NCMCP model, are shown in Fig. 9.

Note that power exchanges increased significantly in almost all periods in order to reduce the differences in average market clearing prices among the areas. However, a difference still remains which is associated with network losses. In order to corroborate this, we artificially set the system losses to null, by eliminating the constraints associated with loss linearization. The new values for average market clearing prices and power exchanges for each period, calculated by the NCMCP model, are shown in Fig. 10.

Therefore, Fig. 10 shows that by eliminating congestion and losses, the impacts of the transmission network are mitigated,

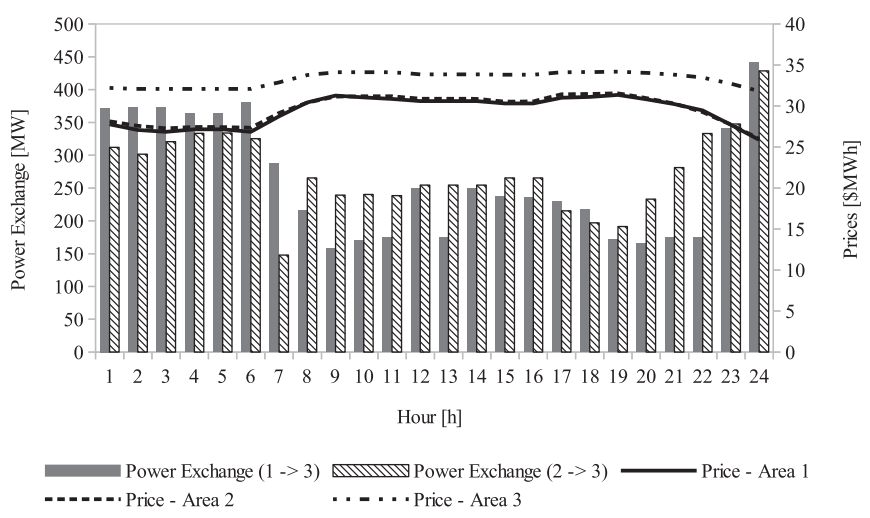

Fig. 9. Average market clearing prices and power exchanges among areas obtained for the 73-bus system-without congestion.

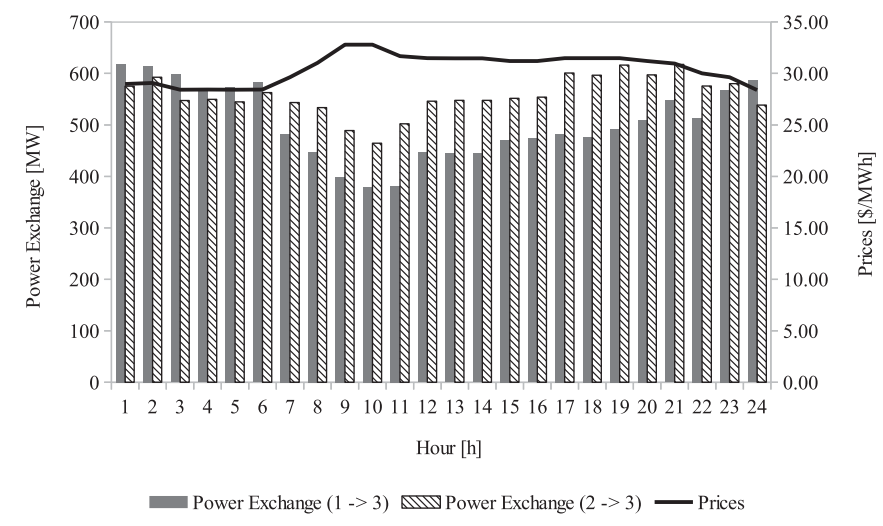

Fig. 10. Average market clearing prices and power exchanges among areas obtained for the 73-bus system-without congestion and losses.

and the average market clearing prices are identical throughout the system. For an "unlimited" transmission, we observe that the energy stored in the reservoirs of Areas 1 and 2 can be reallocated to supply demand in Area 3.

\section{CONCLUSION}

This paper proposes a Network-Constrained Market Clearing Procedure (NCMCP) model for a pool-based energy market of hydrothermal systems, formulated as a mixed-integer linear programming problem. The NCMCP consists of a multiperiod auction model whose objective is to maximize social welfare while taking into account modeling aspects related to a hydrothermal system. The NCMCP model proposed presents the following contributions: i) hydraulic constraints such as nodal water balance, limits on water discharge, spillage and reservoirs volumes, as well as the water release ramp rates are considered in detail; ii) the net head of the reservoir is formulated by appropriate linearization techniques; iii) the hydroelectric power generation function is formulated by means of a three-dimensional interpolation technique which assures good approximations.

Results obtained in the first case study reveal that the representation of hydraulic constraints have a significant impact on market clearing prices as well as on generation and consump- 
tion scheduling. Therefore, neglecting such constraints in the auction model may lead to unrealistic market clearing prices and scheduling and also to short-term decisions that are not coordinated with medium-term generation planning, which may result in future scarcity or waste of water. The second case study evaluates the impact of strategic offering of hydro plants in the operation of a hydraulic cascade. From the results, it is possible to verify an intrinsic operative rule that reallocates water (energy) from the most expensive hydro plants (higher offer prices) to the cheapest ones (lower offer prices), so that the cascade operation is oriented by the offer prices of the hydro plants in the auction. This transfer of water volumes is an interesting operative rule if all plants in the cascade belong to the same generation company. However, if upstream and downstream plants belong to different generation companies, this form of operation may not be so easily accepted, once a company must transfer water to the reservoirs of other companies. On the other hand, once water is a public good it must be used to generate energy as efficiently as possible. It is also important to consider that the decision to generate more or less energy in a given plant is not imposed by the system operator, it is the result of a competitive offer price structure in the auction. Thus, if a company is willing to generate more energy, it should provide more competitive prices in the auction.

The third case study focused on the evaluation of the impact of the transmission system in market clearing prices. For such a purpose, we simulated a three-area network in which two areas were facing a wet season and the other one was facing a drought. The results revealed that the average prices of the areas tend to equalize as long as the transmission system losses and congestion are neglected. As expected, network congestion and losses have a significant impact of system prices.

\section{APPENDIX A \\ THERMAL GENERATION CONSTRAINTS}

In this section we present the thermal constraints described in [1] and [13] and used in the NCMCP model here proposed. Constraints (55)-(57) describe the maximum available power output and ramp rate limits:

$$
\begin{gathered}
\bar{p}_{c}(k) \leq \bar{P}_{c}(k)\left[z_{c}(k)-z d_{c}(k+1)\right] \\
\quad+S D_{c} z d_{c}(k+1), \forall c \in C, \forall k \in\{1, \ldots, T-1\}, \\
\bar{p}_{c}(k) \leq p_{c}(k-1)+R U_{c} z_{c}(k-1)+S U_{c} z u_{c}(k), \\
\forall c \in C, \forall k \in\{2, \ldots, T\} \\
p_{c}(k-1)-p_{c}(k) \leq R D_{c} z_{c}(k)+S D_{c} z d_{c}(k), \\
\forall c \in C, \forall k \in\{2, \ldots, T\} .
\end{gathered}
$$

In (55) and (56) the upper limit of the maximum available power output is defined considering the actual power output, start-up, shut-down and ramp-up rate limits. The constraints (57) set the ramp-down and shut-down ramp rate limits.
The constraints (58)-(60) enforce the minimum up-time. Details concerning the logic of these constraints are given in [1].

$$
\begin{gathered}
\sum_{k=1}^{G_{c}}\left[1-z_{c}(k)\right]=0, \forall c \in C, \\
\sum_{\tau=k}^{k+U T_{c}-1} z_{c}(\tau) \geq U T_{c} z u_{c}(k), \forall c \in C, \\
\forall k \in\left\{G_{c}+1, \ldots, T-U T_{c}+1\right\}, \\
\sum_{\tau=k}^{T}\left[z_{c}(\tau)-z u_{c}(k)\right] \geq 0, \forall c \in C, \\
\forall k \in\left\{T-U T_{c}+2, \ldots, T\right\} .
\end{gathered}
$$

The constraints (61)-(63) enforce the minimum down-time and are analogous to (58)-(60):

$$
\begin{gathered}
\sum_{k=1}^{F_{c}} z_{c}(k)=0, \forall c \in C, \\
\sum_{\tau=k}^{k+D T_{c}-1}\left[1-z_{c}(\tau)\right] \geq D T_{c} z d_{c}(k), \forall c \in C, \\
\quad \forall k \in\left\{F_{c}+1, \ldots, T-D T_{c}+1\right\}, \\
\sum_{\tau=k}^{T}\left[1-z_{c}(\tau)-z d_{c}(k)\right] \geq 0, \forall c \in C, \\
\forall k \in\left\{T-D T_{c}+2, \ldots, T\right\} .
\end{gathered}
$$

\section{APPENDIX B \\ LINEAR NETWORK CONSTRAINTS}

In this section we present the linearization technique described in [5] for the active power flows and losses. The active power flows in a branch $(b, r)$ are represented by nonlinear functions, that are commonly written as in (64) and (65):

$$
\begin{aligned}
& f_{b, r}(k)= P^{\text {base }}\left[\frac{p_{b, r}^{\text {loss }}(k)}{2}+\frac{\delta_{b}(k)-\delta_{r}(k)}{X_{b, r}}\right], \\
& \forall k \in K, \forall(b, r) \in \Lambda, \\
& f_{r, b}(k)=P^{\text {base }}\left[\frac{p_{b, r}^{\text {loss }}(k)}{2}+\frac{\delta_{r}(k)-\delta_{b}(k)}{X_{b, r}}\right], \\
& \forall k \in K, \forall(b, r) \in \Lambda,
\end{aligned}
$$

where the quadratic losses are represented by (66):

$$
\begin{array}{r}
p_{b, r}^{\text {loss }}(k)=G_{b, r}\left[\delta_{b}(k)-\delta_{r}(k)\right]^{2}, \\
\forall k \in K, \forall(b, r) \in \Lambda .
\end{array}
$$


In order to linearize the losses in (66), the constraints (67)-(72) described in [5] are used:

$$
\begin{gathered}
p_{b, r}^{\text {loss }}(k)=G_{b, r} \sum_{\rho=1}^{N B} \alpha_{b, r, \rho} \delta_{b, r, \rho}(k), \\
\forall k \in K, \forall(b, r) \in \Lambda, \\
0 \leq \delta_{b, r, \rho}(k) \leq \Delta \delta_{\rho}, \forall k \in K, \forall(b, r) \in \Lambda, \\
\forall \rho \in\{1, \ldots, N B\}, \\
\delta_{b, r}^{a b s}(k)=\sum_{\rho=1}^{N B} \delta_{b, r, \rho}(k), \forall k \in K, \forall(b, r) \in \Lambda, \\
\delta_{b, r}^{a b s}(k)=\delta_{b, r}^{+}(k)+\delta_{b, r}^{-}(k) \\
\forall k \in K, \forall(b, r) \in \Lambda, \\
\delta_{b, r}^{+}(k)-\delta_{b, r}^{-}(k)=\delta_{b}(k)-\delta_{r}(k), \\
\forall k \in K, \forall(b, r) \in \Lambda, \\
\delta_{b, r}^{+}(k), \delta_{b, r}^{-}(k) \geq 0, \forall k \in K, \forall(b, r) \in \Lambda .
\end{gathered}
$$

The constraints (67)-(69) represent the active power losses as a piece-wise linear function, while (70)-(72) linearize the absolute value of the angular difference in each branch.

\section{ACKNOWLEDGMENT}

The authors would like to thank the referees for their valuable comments and suggestions and also the Fundação de Amparo à Pesquisa do Estado de São Paulo-FAPESP (process numbers 2013/18103-0 and 2013/18036-1) and Coordenação de Aperfeiçoamento de Pessoal de Nível Superior-CAPES.

\section{REFERENCES}

[1] J. Arroyo and A. Conejo, "Multiperiod auction for a pool-based electricity market," IEEE Trans. Power Syst., vol. 17, no. 4, pp. 1225-1231, Nov. 2002.

[2] A. Conejo, F. Galiana, J. Arroyo, R. Garcia-Bertrand, C. W. Chua, and M. Huneault, "Economic inefficiencies and cross-subsidies in an auctionbased electricity pool," IEEE Trans. Power Syst., vol. 18, no. 1, pp. 221228, Feb. 2003.

[3] X. Li, T. Li, J. Wei, G. Wang, and W.-G. Yeh, "Hydro unit commitment via mixed integer linear programming: A case study of the three Gorges project, China," IEEE Trans. Power Syst., vol. 29, no. 3, pp. 1232-1241, May 2014.

[4] A. Borghetti, C. D'Ambrosio, A. Lodi, and S. Martello, "An MILP approach for short-term hydro scheduling and unit commitment with headdependent reservoir," IEEE Trans. Power Syst., vol. 23, no. 3, pp. 11151124, Aug. 2008.

[5] A. Motto, F. Galiana, A. Conejo, and J. Arroyo, "Network-constrained multiperiod auction for a pool-based electricity market," IEEE Trans. Power Syst., vol. 17, no. 3, pp. 646-653, Aug. 2002.

[6] R. Fernandez-Blanco, J. Arroyo, and N. Alguacil, "A unified bilevel programming framework for price-based market clearing under marginal pricing," IEEE Trans. Power Syst., vol. 27, no. 1, pp. 517-525, Feb. 2012.

[7] A. R. L. Oliveira, S. Soares, and L. Nepomuceno, "Short term hydroelectric scheduling combining network flow and interior point approaches," Int. J. Elect. Power Energy Syst., vol. 27, no. 2, pp. 91-99, 2005.

[8] B. Tong, Q. Zhai, and X. Guan, "An MILP based formulation for shortterm hydro generation scheduling with analysis of the linearization effects on solution feasibility," IEEE Trans. Power Syst., vol. 28, no. 4, pp. 35883599, Nov. 2013.
[9] Y. Gu, J. Bakke, Z. Zhou, D. Osborn, T. Guo, and R. Bo, "A novel market simulation methodology on hydro storage," IEEE Trans. Smart Grid, vol. 5, no. 2, pp. 1119-1128, Mar. 2014.

[10] E. K. Aasgard, G. S. Andersen, S.-E. Fleten, and D. Haugstvedt, "Evaluating a stochastic-programming-based bidding model for a multireservoir system," IEEE Trans. Power Syst., vol. 29, no. 4, pp. 1748-1757, Jul. 2014.

[11] C. Simoglou, P. Biskas, and A. Bakirtzis, "A MILP approach to the short term hydrothermal self-scheduling problem," in Proc. IEEE Bucharest PowerTech, Jun. 2009, pp. 1-8.

[12] C. K. Simoglou, P. N. Biskas, and A. G. Bakirtzis, "Optimal selfscheduling of a dominant power company in electricity markets," Int. J. Elect. Power Energy Syst., vol. 43, no. 1, pp. 640-649, 2012.

[13] J. Arroyo and A. Conejo, "Optimal response of a thermal unit to an electricity spot market," IEEE Trans. Power Syst., vol. 15, no. 3, pp. 1098 1104, Aug. 2000.

[14] A. Mas-Colell, M. D. Whinston, and J. R. Green, Microeconomic Theory, London, U.K.: Oxford Univ. Press, 1995.

[15] B. H. Bakken and T. Bjorkvoll, "Hydropower unit start-up costs," in Proc. 2002 IEEE Power Eng. Soc. Summer Meeting, Jul. 2002, vol. 3, pp. 1522 1527.

[16] O. Nilsson and D. Sjelvgren, "Hydro unit start-up costs and their impact on the short term scheduling strategies of Swedish power producers," IEEE Trans. Power Syst., vol. 12, no. 1, pp. 38-44, Feb. 1997.

[17] Operador Nacional do Sistema Elétrico-ONS, "Inventário das restrições operativas hidráulicas dos aproveitamentos hidrelétricos," (in Portuguese), Rio de Janeiro, Brazil, 2013. [Online]. Available: http://www.ons.org.br/home/

[18] J. P. S. Catalão, H. M. I. Pousinho, and V. M. F. Mendes, "Scheduling of head-dependent cascaded reservoirs considering discharge ramping constraints and start/stop of units," Int. J. Elect. Power Energy Syst., vol. 32, no. 8, pp. 904-910, Oct. 2010.

[19] G. F. Bregadioli, E. C. Baptista, L. Nepomuceno, A. R. Balbo, and E. M. Soler, "Medium-term coordination in a network-constrained multi-period auction model for day-ahead markets of hydrothermal systems," Int. J. Elect. Power Energy Syst., vol. 82, pp. 474-483, Nov. 2016.

[20] J. Reneses, E. Centeno, and J. Barquin, "Coordination between mediumterm generation planning and short-term operation in electricity markets," IEEE Trans. Power Syst., vol. 21, no. 1, pp. 43-52, Feb. 2006.

[21] E. Finardi and E. Silva, "Solving the hydro unit commitment problem via dual decomposition and sequential quadratic programming," IEEE Trans. Power Syst., vol. 21, no. 2, pp. 835-844, May 2006.

[22] A. L. Diniz, P. P. I. Esteves, and C. A. Sagastizabal, "A mathematical model for the efficiency curves of hydroelectric units," in Proc. IEEE Power Eng. Soc. General Meeting, Jun. 2007, pp. 1-7.

[23] A. Conejo, J. Arroyo, J. Contreras, and F. Villamor, "Self-scheduling of a hydro producer in a pool-based electricity market," IEEE Trans. Power Syst., vol. 17, no. 4, pp. 1265-1272, Nov. 2002.

[24] P. Wong et al., "The IEEE reliability test system-1996. A report prepared by the reliability test system task force of the application of probability methods subcommittee," IEEE Trans. Power Syst., vol. 14, no. 3, pp. 10101020, Aug. 1999.

[25] “GAMS-Home Page," Washington, DC, USA, Mar. 2016. [Online] Available: https://www.gams.com/

[26] A. J. Conejo, M. Carrin, and J. M. Morales, Decision Making Under Uncertainty in Electricity Markets, vol. 153 (International Series in Operations Research \& Management Science). Boston, MA, USA: Springer, 2010. [Online]. Available: http://link.springer.com/10.1007/978-1-44197421-1

[27] D. S. Kirschen and G. Strbac, Fundamentals of Power System Economics. Hoboken, NJ, USA: Wiley, 2004.

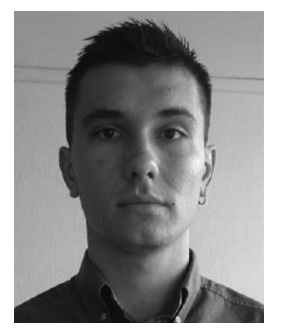

Augusto Cesar Pereira received the Electrical Engineer degree in 2016 from the Universidade Estadual Paulista (UNESP), Bauru, São Paulo, Brazil, where he is currently a M.Sc student in electrical engineering. His research interests include operations, planning and economics of electric power systems. 


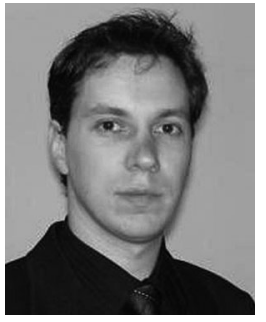

Alberto Quialheiro de Oliveira received the Business Administration degree from Instituição Toledo de Ensino (ITE), Bauru, São Paulo, Brazil, in 2001 and the Mathematics degree in 2012 from the Universidade Estadual Paulista, Bauru, São Paulo, Brazil, where he is currently a M.Sc student in electrical engineering. His research interests include applied optimization.

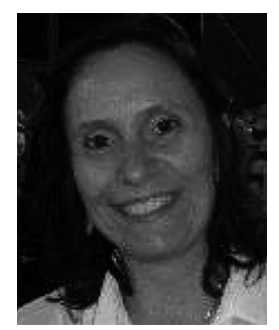

Edméa Cássia Baptista received the Bachelor degree in mathematics, the M.Sc. degree in science computing, and the Ph.D. degree in electrical engineering from the Universidade de São Paulo (USP), São Paulo, Brazil, in 1988, 1993, and 2001, respectively. She is currently a Full Professor in the Department of Mathematics, Science Faculty, Universidade Estadual Paulista (UNESP), Bauru, SP, Brazil. Her areas of expertise involve optimization, nonlinear programming, and its applications to optimal power flow problem and planicity.

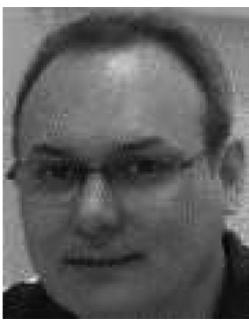

Antonio Roberto Balbo received the Bachelor degree in mathematics from the Universidade Estadual Paulista (UNESP), Bauru, São Paulo, Brazil, in 1986 and the M.Sc. degree in science computing and the $\mathrm{Ph} . \mathrm{D}$. degree in structure engineering from Universidade de São Paulo (USP), Brazil, in 1990 and 1998, respectively. He is currently a Full Professor in the Department of Mathematics, Science Faculty UNESP. His areas of expertise involve nonlinear optimization, multicriteria optimization and the application of primal-dual interior/exterior point methods

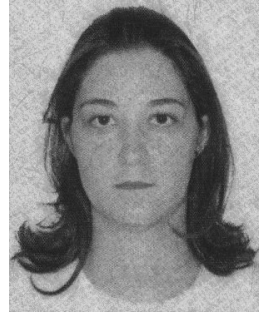

Edilaine Martins Soler received the Bachelor degree in mathematics in 2006, the M.Sc. degree in science computing and computational mathematics in 2008 , and the $\mathrm{Ph}$.D. degree in electrical engineering in 2011, all from the Universidade de São Paulo, Brazil. She is currently working as an Assistant Professor in the Department of Mathematics, Science Faculty, Universidade Estadual Paulista, Bauru, Brazil. Her areas of expertise involve applied optimization, nonlinear optimization, discrete optimization and its applications to the power flow problem.

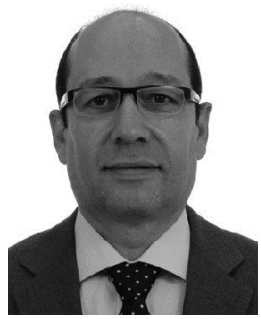

Leonardo Nepomuceno (M'97) received the degree in electrical engineering from the Universidade Federal de Uberlândia, Uberlândia, Brazil, in 1990, and the M.Sc. and Ph.D degrees in electrical engineering from Universidade Estadual de Campinas (UNICAMP), Campinas, Brazil, in 1993 and 1997, respectively. From 1997 to 2000, he worked in a postdoctoral project at UNICAMP. Since 2000, he has been a Full Professor in the Deparment of Electrical Engineering, Engineering Faculty, Universidade Estadual Paulista, Bauru, Brazil. His areas of expertise involve power systems analysis and economics, as well as optimization theory and applications.

to power system optimization. 